\section{Time dependent seismicity along the western coast of Canada}

\section{Evangelos V. Christou, George Karakaisis, Emmanuel Scordilis}

Department of Geophysics, School of Geology, Aristotle University of

Thessaloniki, Greece

\section{Abstract}

Decelerating generation of intermediate magnitude earthquakes (preshocks) in a narrow region (seismogenic region) and accelerating generation of relatively larger such earthquakes in a broader region (critical region) has been proposed as an appropriate model for intermediate-term earthquake prediction. We examined the seismic activity which preceded the $\mathrm{M}_{\mathrm{w}}=7.7$ (October 28, 2012) thrust event that occurred off the west coast of Haida Gwaii, Canada (formerly the Queen Charlotte islands), by applying the decelerating-accelerating seismic strain model. We found that this mainshock was preceded by a pronounced accelerating seismic sequence with the time to the mainshock, as well as by an equally easily identifiable decelerating seismic sequence. Both precursory seismic sequences occurred in different space, time and magnitude windows. The behavior of previous mainshocks that occurred close to the 2012 earthquake was also examined by the time and magnitude predictable regional model.

An attempt was also made to identify such seismic strain patterns, which may also be related to the generation of strong mainshocks along the western coast of Canada.

\section{Introduction}

Strong and large earthquakes along the western coast of Canada are not uncommon. During the instrumental period (since 1898, when the first seismograph of Milne type was installed at Victoria) several $M \geq 7.0$ events occurred there. The majority of the strong earthquakes in this area are associated with the motion between the three major lithospheric plates, namely Pacific, North America and Juan de Fuca (Figure 1). The boundary between Pacific and North America plates is a right lateral transform fault (Queen Charlotte Fault, QCF) that extends from Vancouver Island up to Alaska and the Fairweather Fault (FF), whereas the boundary between Juan de
Fuca and North America plates corresponds to the Cascadia subduction zone (CSZ), where the giant M9 earthquake occurred in 1700 .

The present study was motivated by the occurrence of the 2012 Haida Gwaii islands (formerly the Queen Charlotte islands) earthquake $(\mathrm{M}=7.7)$. This was the first major thrust event recorded along the strike-slip QCF. ${ }^{1}$ In this article we present the results of the application of two time-dependent seismicity models in an attempt to retrospectively predict the 2012 mainshock. Moreover, we apply both models searching for future strong earthquakes along the western coast of Canada.

\section{Models applied and data}

The first of the two time-dependent seismicity models is based on the triggering of a mainshock by its preshocks and is called decelerating-accelerating seismic strain (D-AS) model. There is reliable evidence that an increase in the occurrence rate of intermediate-magnitude shocks has been observed in a broad area before strong earthquakes. ${ }^{2-8}$ Recently, however, skepticism has been expressed on the reliability of these observations, ${ }^{9,10}$ which is discussed later. Quantification of the accelerating pattern of these earthquakes that occur in this broad region before a mainshock, ${ }^{11}$ showed that the cumulative Benioff strain, $\mathrm{S}(\mathrm{t})$, can be expressed by the following power law:

$$
S(t)=A+B\left(t_{c}-t\right)^{m}
$$

where $t_{c}$ is the origin time of the mainshock and $\mathrm{A}, \mathrm{B}, \mathrm{m}$, are parameters calculated by the available data (with $\mathrm{m}<1, \mathrm{~B}<0$ ). The quantity $\mathrm{S}(\mathrm{t})$, which is considered as a measure of the preshock seismic deformation at time $t$, is defined as $S(t)=\sum_{i=1}^{n(t)} E_{i}^{1 / 2}$, where $E_{i}$ is the seismic energy of the $i$ th preshocks and $n(t)$ is the number of preshocks occurred up to time $t$. On the other hand, it has also been observed that in the narrow (focal) region of an ensuing mainshock, a seismic excitation is followed by a drop of seismicity, i.e., a seismic quiescence period. ${ }^{12,13}$ Global data were used ${ }^{14}$ to show that intermediate magnitude preshocks in the focal region form a decelerating pattern and that the time variation of the cumulative Benioff strain up to the mainshock also follows a power-law (relation 1) but with a power value larger than one $(m>1)$. That is, this pattern of decelerating strain in the focal region is formed of a seismic excitation followed by a decrease of seismicity of intermediate magnitude preshocks.

The formulation of the D-AS model for intermediate-term earthquake prediction was based on the examination of the patterns described above, which preceded strong
Correspondence: Evangelos Christou, Planetary Sciences Humboldt Universität zu Berlin, Jablonskistraße 14, Berlin, Germany.

Tel.: +49.15258299952.

E-mail: aggelosvchristou@gmail.com

Key words: Time dependent seismicity; Canada; Haida Gwaii 2012 earthquake.

Acknowledgements: Evangelos Christou gratefully acknowledges Dr. G. Papadopoulos (Chair) and the Organizing Committee of the International Workshop Mega Earthquakes and Tsunamis in Subduction Zones for the financial support. Maps were made using Generic Mapping Tools GMT 4.5 (Wessel and Smith, 1998). We used data from the National Resources Canada (On-line Bulletin), http://earthquakescanada.nrcan.gc.ca/stndon/NE DB-BNDS/bull-eng.php, Nat. Res. Can., (last accessed: July 23, 2014). We thank the anonymous reviewer for the helpful comments and suggestions.

Conference presentation: this work has been presented in the International Workshop Mega Earthquakes and Tsunamis in Subduction ZonesForecasting Approaches and Implications for Hazard Assessment, held in Rhodes Island, Greece (2014).

Received for publication: 24 November 2014 Revision received: 6 December 2015

Accepted for publication: 22 December 2015.

This work is licensed under a Creative Commons Attribution NonCommercial 4.0 License (CC BYNC 4.0).

(C) Copyright E.V. Christou et al., 2016

Licensee PAGEPress, Italy

Research in Geophysics 2016; 5:5730

doi:10.4081/rg.2016.5730

( $\mathrm{M}=6.3-9.0)$ shallow $(\mathrm{h}<100 \mathrm{~km})$ mainshocks worldwide. ${ }^{15}$ Tests performed on synthetic catalogues $^{15,16}$ and retrospective predictions of recent strong mainshocks have been used to evaluate the model whereas forward tests led to the successful intermediate-term prediction of two strong earthquakes in the Aegean. ${ }^{17,18}$ During the formulation of the D-AS model it was observed that each of the investigated mainshocks was preceded by a decelerating preshock sequence, generated in a relatively small region (seismogenic region) where the mainshock is also located, and by an accelerating preshock sequence generated in a broader region (critical region) and that both precursory seismic sequences have predictive properties, related to the ensuing mainshock. Decelerating preshocks occur in different time, magnitude and space windows than the accelerating preshocks. The latter start earlier than the former $\left(t_{\mathrm{sa}}>\mathrm{t}_{\mathrm{sd}}\right)$, and their magnitudes are larger the magnitudes of the decelerating 
preshocks. The strain acceleration, $\mathrm{q}_{\mathrm{a}}$, as well as the strain deceleration, $q_{d}$, (also called quality indexes), vary with the time to the mainshock. ${ }^{17}$ Both start with low values, attain their largest values several years before the mainshock occurrence and cease gradually about three years before the mainshock, i.e., the seismic activity declines in the critical region and increases in the seismogenic region.

The radii $\mathrm{r}(\mathrm{km})$ of the seismogenic region and $\mathrm{R}(\mathrm{km})$ of the critical region, which are assumed circular, are given by the relations: ${ }^{15}$

$\log r=0.23 \cdot M-0.14 \cdot \log s_{d}+1.40 \quad \sigma=0.15$

$\log \mathrm{R}=0.42 \cdot \mathrm{M}-0.30 \cdot \log \mathrm{s}_{\mathrm{a}}+1.25 \quad \sigma=0.16$

with $\mathrm{M}$ being the mainshock magnitude and $\mathrm{s}_{\mathrm{d}}$ and $s_{\mathrm{a}}$ (in $\mathrm{J}^{1 / 2} / \mathrm{y} \times 10^{4} \mathrm{~km}^{2}$ ) is the Benioff strain in the seismogenic and critical region, respectively.

The following two relations hold also for the decelerating and accelerating preshock sequences: ${ }^{15}$

$$
\begin{aligned}
& \operatorname{og}\left(t_{c}-t_{s d}\right)=2.95-0.31 \cdot \log s_{d} \quad \sigma=0.12 \\
& \log \left(\mathrm{t}_{\mathrm{c}}-\mathrm{t}_{\mathrm{sa}}\right)=4.60-0.57 \cdot \log \mathrm{s}_{\mathrm{a}} \quad \sigma=0.17
\end{aligned}
$$

where $t_{s d}$ and $t_{s a}$ are the start times (in years) of the decelerating and accelerating preshock sequence, respectively.

The curvature parameter, $\mathrm{C}$, has been proposed $^{19}$ as a measure of accelerating strain release and equals to the ratio of the RMS error of the power-law fit (Eq. 1) to the corresponding linear fir error. $\mathrm{C}$ takes positive values smaller than 1, becomes equal to 1 for linear fit and decreases when the accelerating Benioff strain release becomes more intense. A quality index, $q_{a}$, has been defined to measure the intensity of the accelerating pattern: ${ }^{20}$

$$
\mathrm{q}_{\mathrm{a}}=\frac{\mathrm{P}_{\mathrm{a}}}{\mathrm{m}_{\mathrm{a}} \cdot \mathrm{C}_{\mathrm{a}}}
$$

where $\mathrm{m}_{\mathrm{a}}$ is the exponent in relation (1), $\mathrm{C}_{\mathrm{a}}$ is the curvature parameter and $\mathrm{P}_{\mathrm{a}}$ is the probability that an accelerating pattern fulfills relations (3) and (5). A similar relation quantifies the intensity, $q_{d}$, of the decelerating strain:

$$
\mathrm{q}_{\mathrm{d}}=\frac{\mathrm{P}_{\mathrm{d}} \cdot \mathrm{m}_{\mathrm{d}}}{\mathrm{C}_{\mathrm{d}}}
$$

with $m_{d}$ being the exponent in relation (1) for the decelerating pattern, $C_{d}$ is the curvature parameter and $P_{d}$ is the probability that a decelerating strain release fulfils relations (2) and (4). Both quality indexes $q_{d}$ and $q_{a}$ are very useful in searching for decelerating and accelerating seismicity patterns since they attain their largest values at the seismogenic and critical region, respectively. Global observations ${ }^{15}$ resulted in the following cut-off values of the parameters that describe the decelerating and the accelerating precursory seismic sequences:

$$
\begin{aligned}
& C_{d} \leq 0.60, \quad P_{d} \geq 0.45, \quad q_{d} \geq 3.00, \quad 2.5 \leq m \leq 3.5 \\
& C_{a} \leq 0.70, \quad P_{a} \geq 0.45, \quad q_{a} \geq 3.00, \quad 0.25 \leq m \leq 0.35
\end{aligned}
$$

The second of the models applied in the present work makes use of interevent times of strong earthquakes in an area, which depend on the rate of tectonic loading. However, since such earthquakes, that occur on a single fault, usually have recurrence times much larger than the relatively short span of the earthquake catalogues used, it is preferable to consider seismogenic sources, i.e., circular regions that include, in addition to the main fault where the largest mainshock occurs, other smaller faults where smaller mainshocks occur. On the basis of this idea, the time and magnitude predictable regional (TIMAPR) model has been proposed, ${ }^{21}$ which makes use of numerous interevent times of strong earthquakes (mainshocks) generated in a region, in order to investigate the time-dependent seismicity of this region. This model has been developed by considering a large sample of global data, ${ }^{21}$ which was used to derive the following two equations that relate the interevent time, $\mathrm{T}_{\mathrm{t}}$ (in years), until the next mainshock and its expected magnitude, $\mathrm{M}_{\mathrm{f}}$, to the magnitude, $\mathrm{M}_{\mathrm{p}}$, of the previous mainshock in the region examined, the long-term seismicity level, $S_{d}$ (the seismic strain rate in Joule ${ }^{1 / 2}$ per year) and the minimum mainshock magni-

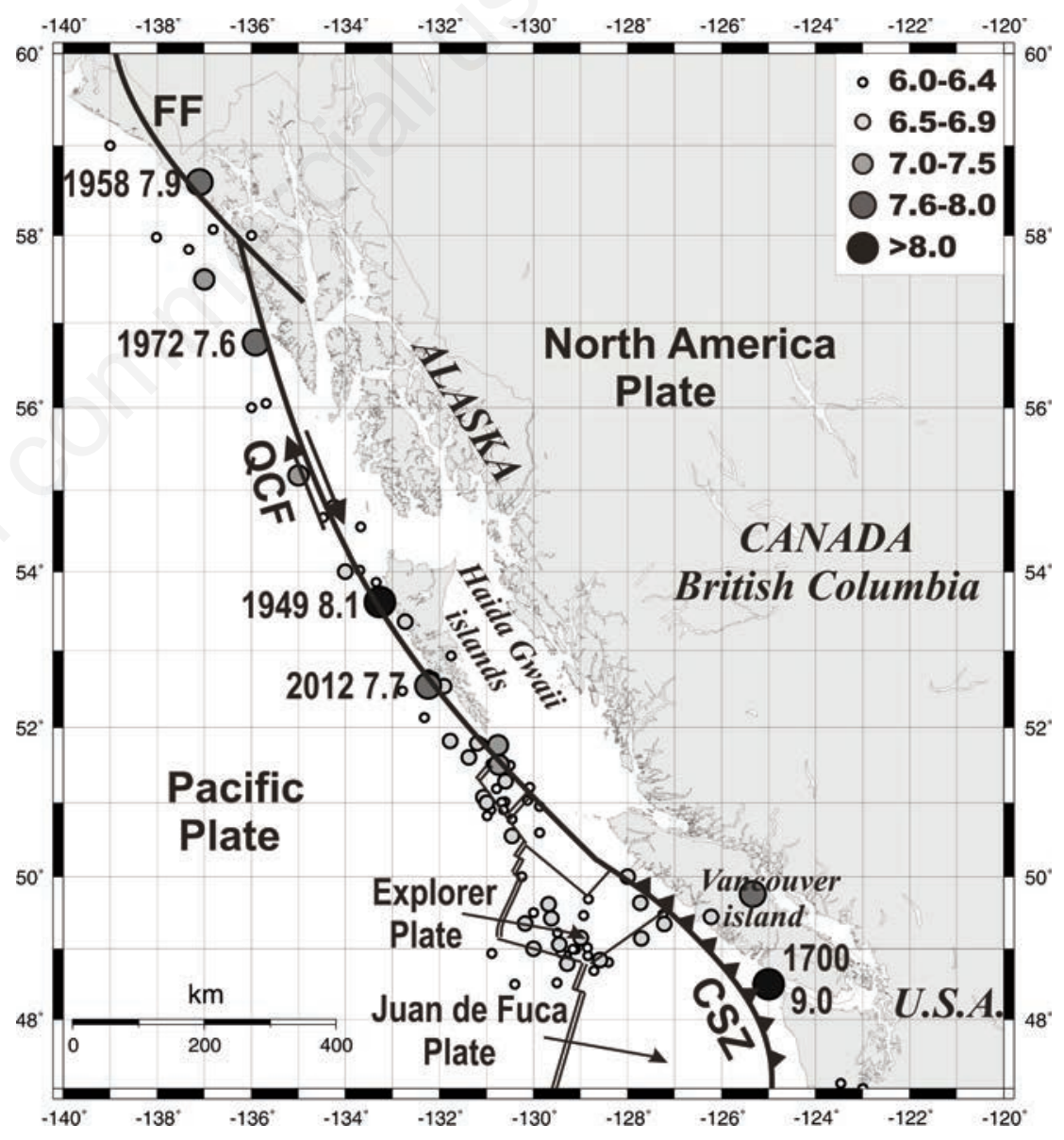

Figure 1. Main tectonic features of the studied area. FF, Fairweather Fault; QCF, Queen Charlotte Fault; CSZ, Cascadia Subduction Zone. Epicenters of all earthquakes with $M \geq 6.0$ that occurred after 1912 are shown along with the epicenter of the giant M9 of 1700 in Cascadia. 
tude, $\mathrm{M}_{\min }$, considered:

$\log \mathrm{T}_{\mathrm{t}}=0.19 \cdot \mathrm{M}_{\min }+0.33 \cdot \mathrm{M}_{\mathrm{p}}-0.54 \cdot \log \mathrm{S}_{\mathrm{d}}+\mathrm{q}$

$\mathrm{M}_{\mathrm{f}}=0.73 \cdot \mathrm{M}_{\min }-0.28 \cdot \mathrm{M}_{\mathrm{p}}+0.46 \cdot \log \mathrm{S}_{\mathrm{d}}+\mathrm{w}$

The mean values of $q$ and $w$ and their standard deviations $\sigma / \mathrm{q}$ and $\sigma_{\mathrm{w}}$ can be calculated by the available data for a certain seismogenic source. It was showed ${ }^{22}$ that the ratio $\sigma / T_{t}$ of the observed interevent time, $\mathrm{T}$, to the calculated, $\mathrm{T}_{\mathrm{t}}$ (by Eq. 10), follows a lognormal distribution with a mean equal to zero. The application of this model requires a declustered catalogue of mainshocks, which is derived after adopting an appropriate time window, defined by the ratio $\sigma / \mathrm{T}$ (where $\mathrm{T}$ is the mean interevent time and $s$ its standard deviation), since this ratio is a measure of seismic clustering. For ratio values smaller than 0.5 an earthquake catalogue exhibits quasi-periodic behaviour. ${ }^{23}$ Global data show that for a time window $\Delta t \geq 15$ years this ratio becomes smaller than $0.5^{24}$

The procedure followed for creating a mainshock catalogue in a seismogenic source through declustering starts after considering the largest earthquake of the available complete earthquake catalogue of the source as the first mainshock. This mainshock and its associated shocks (earthquakes of the original catalogue that occurred in the seismogenic source within a time window \pm 15 years from the mainshock origin time) are excluded from the original catalogue. Then, the largest earth- quake of the remaining catalogue is considered as a mainshock and its associated shocks, defined as previously, are also excluded from the catalogue. This continues till no event with magnitude larger than a certain cut-off magnitude $\mathrm{M}_{\text {min }}$ remains in the original catalogue. For the identification of a circular seismogenic source the examined area is covered by a dense grid of geographic points. Each point is considered as the center, $\mathrm{K}$, of a circular seismogenic source and circles with varying radius (e.g., $\mathrm{r}=30-200 \mathrm{~km}$ ) are defined. The earthquake catalogue for each circle is declustered according to the procedure described previously and relations (10) and (11) is applied on the resulting mainshocks. The optimum seismogenic source is selected for the circle $(K, r)$ for which the optimization factor, $\mathrm{OP}=\frac{\sqrt{\mathrm{N}}}{\sigma_{\mathrm{q}}}$, where $\mathrm{N}$ is the number of interevent times, has the largest value $(\mathrm{N} \geq 3)$. In the present case the geographic point with the highest $\mathrm{OP}$ value in the vicinity of the 2012 earthquake is $51.6^{\circ} \mathrm{N}-131.0^{\circ} \mathrm{W}$, with $\mathrm{OP}=19.35$ and $\mathrm{r}=180 \mathrm{~km}$. The declustered mainshock catalogue within this seismogenic source, which will be subsequently used for the retrospective prediction of the 2012 event, includes the following shocks: $1912 \mathrm{M}=6.5,1929 \mathrm{M}=7.0,1949 \mathrm{M}=8.1,1970$ $\mathrm{M}=7.4,1992 \mathrm{M}=6.7$.

Data used in the present work have been extracted from the Seismic Hazard Earthquake Epicenter File (SHEEF) for the period 1627$1991^{25}$ and from the National Resources
Canada on-line bulletin (http://earthquakescanada.nrcan.gc.ca/stndon/NEDB-BNDS/bulleng.php, last accessed: July 23, 2014) for the period 1992-2014. The studied area is bounded by the $120^{\circ} \mathrm{W}-140^{\circ} \mathrm{W}$ meridians and $47^{\circ} \mathrm{N}-57^{\circ} \mathrm{N}$ parallels. Earthquake magnitudes are mainly expressed in the $M_{L}, M_{S}$ and $m_{b}$ scales and $M_{w}$ for recent events. Although earthquake detectability studies ${ }^{26}$ suggest that the earthquake catalogue for the examined area may be assumed to be complete for $\mathrm{M} \geq 5.0$ since 1951 and $M \geq 4.0$ since 1971 , we used the ZMAP software $^{27}$ as well as the traditional frequencymagnitude distribution ${ }^{28}$ to check space and time variations of magnitude completeness. We found that the data are complete for the whole area under investigation for $M \geq 4.8$ for the time interval $1960-1990$ and for $M \geq 4.0$ for the time interval 1991-2014. To ensure homogeneity of the catalogue in respect to the magnitude, $m_{b}$ and $M_{S}$ magnitudes were converted into the moment magnitude scale, $M_{w}$, by appropriate relations derived by the use of global data, ${ }^{29,30}$ whereas $\mathrm{M}_{\mathrm{L}}$ magnitudes were converted to $M_{w}$ using the relations valid for western Canada. ${ }^{31}$

\section{Results}

Previous studies ${ }^{15,16,24,32}$ showed that the centers $F(\varphi, \lambda)$ and $Q(\varphi, \lambda)$ of the seismogenic and critical regions, respectively, are located in areas bounded by the two parallels

\section{A}

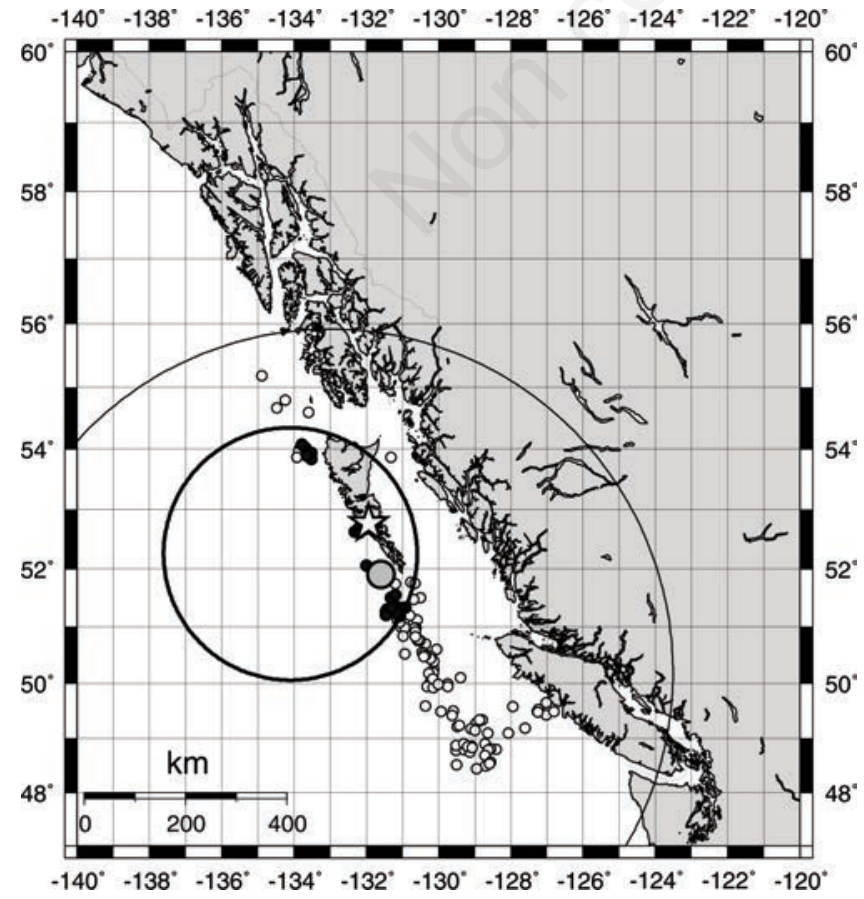

B

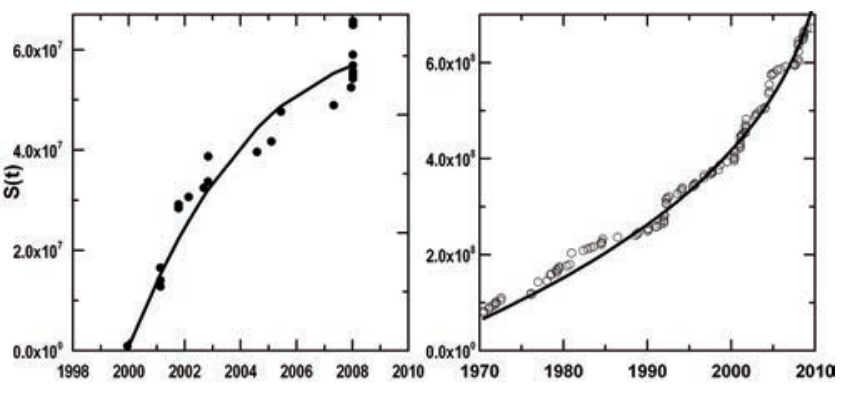

Figure 2. A) Decelerating (dots) and accelerating (small open circles) preshocks of the 2012 mainshock (denoted by a star) that occurred within the circular seismogenic and critical regions, respectively. The retrospectively predicted epicenter is denoted by the grey circle. B) Plots of the time variation of the decelerating (left) and accelerating Benioff strain release, $S(t)$ (right), are also shown at the lower part of the figure, along with the curves that fit the data. 
$\varphi \pm 3^{\circ} \mathrm{NS}$ and the meridians $\lambda \pm 3^{\circ} \mathrm{EW}$ around the mainshock epicenter, $\mathrm{E}(\varphi, \lambda)$. For this reason each of these areas is covered by a dense grid of points (e.g., $\left.\pm 0.2^{\circ} \mathrm{NS}, \pm 0.2^{\circ} \mathrm{EW}\right)$. In order to define the seismogenic region, where the decelerating Benioff strain release may be observed, each of these points is considered as the center of a circular seismogenic region with radius $r$ (given by relation 2 ). For various $\mathrm{r}$-values, $\mathrm{t}_{\mathrm{sd}}$ start times and minimum magnitudes, different quality index, $q_{d}$, values are calculated. The geographic point where the largest of these values is found, corresponds to the center, $\mathrm{F}$, of the seismogenic region. The same procedure is applied for the definition of the circular critical region with radius $R$ (given by relation 3 ), and the geographic point where the largest quality index, $q_{a}$, is calculated, corresponds to the center of the critical region where accelerating preshocks occurred prior to the mainshock generation.

Table 1 gives information on the properties of the decelerating and accelerating preshocks that preceded the 2012 Haida Gwaii mainshock and occurred within the corresponding seismogenic and circular regions. The first three columns list the origin time, magnitude and epicenter coordinates of the mainshock and the next two columns show the centers, F, Q, and radii $r, R$, of the circular seismogenic and critical regions, respectively. The minimum preshock magnitudes, $\mathbf{M}_{\min }$, and the start years of the decelerating, $t_{s d}$, and the accelerating, $t_{\text {sa }}$, preshock sequences are shown in the sixth and seventh columns. The last three columns show the values of the curvature parameter, $\mathrm{C}$, for the decelerating and accelerating preshocks, the logarithm of the strain rate, $s_{d}$ and $s_{\mathrm{a}}$ (in Joules per year and per $10^{4} \mathrm{~km}^{2}$ ) and the values of the quality indexes $q_{a}$ and $q_{d}$, given by the relations (6) and (7).

The spatial distribution of the decelerating (dots) and accelerating (small open circles) preshocks of the 2012 mainshock (denoted by a star) that occurred within the circular seismogenic and critical regions, respectively, is shown in Figure 2. The retrospectively predicted epicenter is denoted by the grey circle. Plots of the time variation of the decelerating (Figure 2B left) and accelerating Benioff strain release, $\mathrm{S}(\mathrm{t})$ (Figure 2B - right), are also shown at the lower part of the figure, along with the curves that fit the data. Both preshock sequences end three years before the mainshock.

The finally adopted as predicted origin time, $\mathrm{t}^{*}$, magnitude, $\mathrm{M}^{*}$, and epicenter, $\mathrm{E}^{*}(\phi, \lambda)$, of the retrospectively predicted mainshock, which are given in the last row of Table 1, have been estimated in the following way. The origin time, $\mathrm{t}^{*}$, is the mean value of the times calculated by the relations (4), (5) and (10) (the recurrence interval, $\mathrm{T}_{\mathrm{t}}$, calculated by the last relation, is added to the origin time of the previous mainshock that occurred in the region). The magnitude, $\mathrm{M}^{*}$, is the mean of the magnitude values calculated by the relations (2), (3), and (11). Finally, the epicenter, $\mathrm{E}^{*}(\phi, \lambda)$, is the mean of two geographic points: i) the mean epicenter of the decelerating preshocks; ii) the mean epicenter of the mainshocks which were identified after declustering the original complete catalogue of earthquakes that occurred in the seismogenic source. The difference between the observed and the calculated basic focal parameters, in the present work, are within the model uncertainties, i.e., $\mathrm{t}^{*}: \pm 2.5$ years, $\mathrm{M}^{*} \pm 0.3, \mathrm{E}^{*}: 80 \pm 30 \mathrm{~km} .{ }^{15,24}$

In an attempt to search for precursory decelerating and accelerating preshock sequences that may be related to the generation of a future strong earthquake, the area bounded by the $48.0^{\circ} \mathrm{N}-57^{\circ} \mathrm{N}$ parallels and $122^{\circ} \mathrm{W}-138^{\circ} \mathrm{W}$ meridians was covered by a grid of points spaced $0.5^{\circ}$ apart. The magnitude range of the probably ensuing earthquake was set between 7.0 and 8.2 with step equal to 0.2 magnitude units. Table 2 lists the basic parameters concerning decelerating and accelerating preshock sequences, which may be related to a probably ensuing mainshock. Figure 3 shows the spatial distribution of the decelerating and accelerating preshocks along with the time variation of the respective cumulative Benioff strain, $\mathrm{S}(\mathrm{t})$.

Following the procedure described previously, the basic focal parameters of this earthquake were estimated: i) expected origin time $\mathrm{t}_{\mathrm{c}}{ }^{*}=2022.5$; ii) expected magnitude $\mathrm{M}^{*}=7.1$; iii) expected epicenter coordinates $\mathrm{E}^{*}=49.4^{\circ} \mathrm{N}, 129.6^{\circ} \mathrm{W}$.

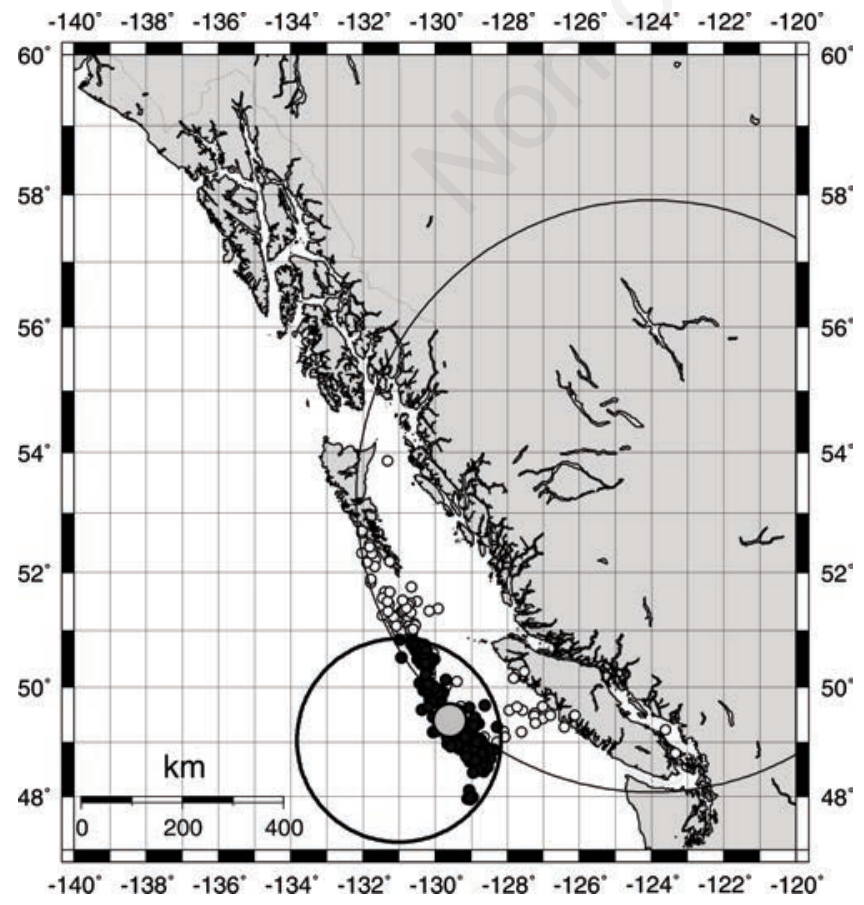

B
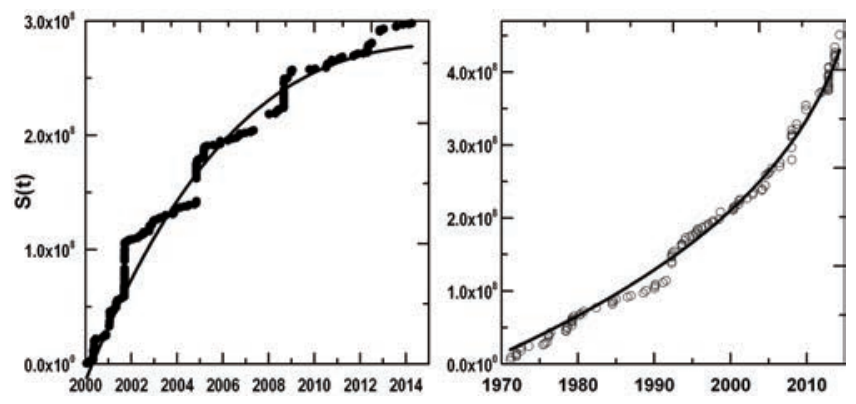

Figure 3. A) Decelerating (dots) and accelerating (small open circles) preshocks associated with the probably expected earthquake (grey circle) in area studied. B) Plots of the time variation of the decelerating (left) and accelerating Benioff strain release, $S(t)$ (right), are also shown at the lower part of the figure, along with the curves that fit the data. 
Table 1. Properties of the decelerating and accelerating preshocks and their respective circular regions. Date, magnitude and epicenter coordinates of the 2012 mainshock are listed in the first three columns. The centers, F, and $Q$ of the seismogenic and critical regions, along with their corresponding radii, $r$ and $R$, are then shown. Information follows on the minimum magnitude, $M_{\text {min }}$, the start times, $t_{s d}$ and $t_{s a}$, and the values of the curvature parameter of the decelerating and accelerating preshocks. The last two columns show the logarithm of the strain rate, $s_{d}$ and $s_{a}$ (in Joules per year and per $10^{4} \mathbf{k m}^{2}$ ) and the values of the quality indexes $q_{d}$ and $q_{a}$. In the last row the origin time, $t^{*}$, magnitude, $\mathbf{M}^{*}$, and epicenter, $\mathrm{E}^{*}(\varphi, \lambda)$, that were calculated in the present work, for this mainshock, are given.

\begin{tabular}{|c|c|c|c|c|c|c|c|c|c|}
\hline Date & M & $\mathrm{E}(\varphi, \lambda)$ & $\mathbf{F}(\varphi, \lambda)$ & $\mathrm{r}(\mathrm{km})$ & $\mathbf{M}_{\min }$ & $t_{s d}$ & C & $\log _{d}$ & $\mathrm{q}_{\mathrm{d}}$ \\
\hline \multirow[t]{3}{*}{ 2012.10.28 } & 7.7 & $52.8-132.9$ & $52.2-134.1$ & 239 & 4.6 & 1998 & 0.53 & 5.19 & 3.6 \\
\hline & & & $\mathbf{Q}(\phi, \lambda)$ & $\mathrm{R}(\mathrm{km})$ & $\mathbf{M}_{\min }$ & $t_{\mathrm{sa}}$ & C & $\log _{a}$ & $q_{a}$ \\
\hline & & & $49.8-133.0$ & 680 & 5.3 & 1968 & 0.38 & 5.18 & 7.3 \\
\hline $\mathrm{t}^{*}$ & $\mathrm{M}^{*}$ & $\mathbf{E}^{*}(\varphi, \lambda)$ & & & & & & & \\
\hline 2014.1 & 7.4 & 51.9-131.6 & & & & & & & \\
\hline
\end{tabular}

Table 2. Properties of the decelerating and accelerating preshocks and their respective circular regions, which may be related to a probably ensuing strong earthquake in the area examined. In the last row the basic focal parameters $E^{*}(\varphi, \lambda)$, $t^{*}$, and $\mathbf{M}^{*}$, of this earthquake are given.

\begin{tabular}{|c|c|c|c|c|c|c|}
\hline$F(\varphi, \lambda)$ & r (km) & $\mathbf{M}_{\min }$ & $t_{s d}$ & C & $\log s_{d}$ & qd \\
\hline $52.2-134.1$ & 239 & 4.6 & 1998 & 0.53 & 5.19 & 3.6 \\
\hline $\mathbf{Q}(\varphi, \lambda)$ & R (km) & $\mathbf{M}_{\min }$ & $t_{\mathrm{sa}}$ & C & $\log s_{a}$ & $q_{a}$ \\
\hline $49.8-133.0$ & 680 & 5.3 & 1968 & 0.38 & 5.18 & 7.3 \\
\hline $\mathbf{E}^{*}(\varphi, \lambda)$ & $t^{*}$ & $M^{*}$ & & & & \\
\hline 49.4-129.6 & 2022.5 & 7.1 & & & & \\
\hline
\end{tabular}

\section{Discussion and Conclusions}

We found that decelerating strain, released by intermediate magnitude preshocks, which occurred within a narrow region, along with accelerating strain released by larger shocks in a broader region, preceded the 2012 Haida Gwaii earthquake. We also found that the mainshocks, which occurred in the seismogenic source, where the 2012 epicenter is located, follow a quasi-periodic pattern which allows the estimation of occurrence time and magnitude of the next mainshock by the use of the magnitude and the occurrence time of the previous mainshock. Moreover, we searched the studied area for currently deceleratingaccelerating strain release, which may be related with a probably ensuing mainshock.

We cannot ignore the skepticism expressed during the last several years about the hypothesis of accelerating seismicity that this pattern may arise from a combination of data fitting and from the generation of normal foreshocks and aftershocks ${ }^{9}$ or that it may be due to the formulation of the accelerating preshock generation as a power-law fit to a cumulative seismicity series. ${ }^{10}$ The negative results reported as regards the statistical significance of the AMR hypothesis, ${ }^{9}$ may be due to the optimization procedure applied, in examining acceler- ating shocks that occurred in circular areas centered at the mainshock epicenter, which was based solely on minimizing the curvature parameter C. Recent tests on synthetic catalogues of earthquakes with spatiotemporal clustering based on the ETAS model in Aegean and California ${ }^{16}$ showed that decelerating and accelerating sequences are hardly recognizable in circular regions centered at the mainshock epicenter (low $q_{d}$ and $q_{a}$ values), in accordance with the negative results mentioned above, ${ }^{9}$ whereas such sequences are easily identifiable in circular areas with centers close to the mainshock epicenter.

\section{References}

1. Cassidy JF, Rogers GC, Hyndman RD. An overview of the 28 October 2012 Mw7.7 earthquake in Haida Gwaii, Canada: a tsunamigenic thrust event along a predominantly strike-slip margin. Pure Appl Geophys 2014 [Epub ahead of print].

2. Imamura A. Theoretical and applied seismology. Tokyo: Maruzen; 1937.

3. Gutenberg B, Richter CF. Seismicity of the Earth and associated phenomena. New York: Hafner; 1954.

4. Tocher D. Seismic history of the San
Francisco bay region. Calif Div Mines Spec Rep 1959;57:39-48.

5. Papadopoulos GA. Long-term accelerating foreshock activity may indicate the occurrence time of a strong shock in the Western Hellenic Arc. Tectonophysics 1988;152:179-92.

6. Jaumé SC, Sykes LR. Evolving towards a critical point: a review of accelerating seismic moment/energy release rate prior to large and great earthquakes. Pure appl Geophys 1999;155:279-306.

7. Papazachos CB, Karakaisis GF, Scordilis EM, et al. Global observational properties of the critical earthquake model. B Seismol Soc Am 2005;95:1841-55.

8. De Santis A, Cianchini G, Di Giovabatista R. Accelerating moment release revisited: Examples of application to Italian seismic sequences. Tectonophysics 2015;639:8298.

9. Hardebeck JL, Felzer KR, Michael AJ. Improved tests reveal that the accelerating moment release hypothesis is statistically insignificant. J Geophys Res 2008;113: 808310

10. Mignan A. Retrospective on accelerating seismic release (ASR) hypothesis: Controversy and new horizons. Tectonophysics 2011;505:1-16.

11. Bufe CG, Varnes DJ. Predictive modeling of 
seismic cycle of the Great San Francisco Bay Region. J Geophys Res 1993;98:9871-83.

12. Evison FF, Rhoades DA. The precursory earthquake swarm in New Zealand. $\mathrm{N} Z \mathrm{~J}$ Geol Geophys 1997;40:537-47.

13. Evison FF. Long-range synoptic earthquake forecasting: an aim for the millennium. Tectonophysics 2001;333:207-15.

14. Papazachos CB, Scordilis EM, Karakaisis GF, et al. Decelerating preshock seismic deformation in fault regions during critical periods. B Geol Soc Greece 2005;36:1490-8.

15. Papazachos CB, Karakaisis GF, Scordilis $\mathrm{EM}$, et al. New observational information on the precursory accelerating and decelerating strain energy release. Tectonophysics 2006;423:83-96.

16. Karakaisis GF, Papazachos CB, Scordilis EM. Recent reliable observations and improved tests on synthetic catalogs with spatiotemporal clustering verify precursory decelerating-accelerating seismicity. J Seismol 2013;17:1063-72.

17. Papazachos BC, Karakaisis GF, Papazachos CB, et al. Evaluation of the results for an intermediate term prediction of the 8 January $2006 \mathrm{Mw}=6.9$ Cythera earthquake in southwestern Aegean. B Seismol Soc Am 2007;97:347-52.

18. Papazachos BC, Karakaisis GF,
Papazachos CB, et al. A forward test of the decelerating-accelerating seismic strain model in the Mediterranean. Boll Geofis Teor Appl 2009;50:235-54.

19. Bowman DD, Quillon G, Sammis CG, et al. An observational test of the critical earthquake concept. J Geophys Res 1998; 103:24359-72.

20. Papazachos CB, Karakaisis GF, Savvaidis $\mathrm{AS}$, et al. Accelerating seismic crustal deformation in the southern Aegean area. B Seismol Soc Am 2002;92:570-80.

21. Papazachos BC, Papadimitriou EE, Karakaisis GF, et al. Long-term earthquake prediction in the Circum-Pacific convergent belt. Pure Appl Geophys 1997;149:173217.

22. Papazachos BC, Papaioannou ChA. Long term earthquake prediction in the Aegean area based on the time and magnitude predictable model. Pure Appl Geophys 1993;140:593-612.

23. Kagan YY, Jackson DD. Long-term earthquake clustering. Geophys J Int 1991;104:117-33.

24. Papazachos BC, Karakaisis GF, Scordilis EM. Time dependent seismicity in the continental fracture system. Boll. Geofis Teor Applic 2014;55:617-39.

25. Halchuk S. Seismic Hazard Earthquake Epicenter File (SHEEF) used in the fourth generation seismic hazard maps of Canada. Geological Survey of Canada, Open File 6208 2009; pp 16.

26. Milne WG, Rogers GC, Riddihough RP, et al. Seismicity of western Canada. Can J Earth Sci 1978;15:1170-93.

27. Wiemer S. A software package to analyze seismicity: ZMAP. Seis Res Letts 2001;72: 374-83.

28. Gutenberg B, Richter CF. Frequency of earthquakes in California. B Seismol Soc Am 1944;34:185-8.

29. Scordilis EM. Globally valid relations converting Ms, mb and MJMA to Mw, at Meeting on earthquake monitoring and seismic hazard mitigation in Balkan countries. NATO ARW, 11-17 September 2005, Borovetz, Bulgaria, pp 158-161.

30. Scordilis EM. Empirical global relations converting Ms and mb to moment magnitude. J Seismology 2006;10:225-36.

31. Ristau JP. Seismotectonics of western Canada from regional moment tensor analysis. PhD Thesis, University of Victoria, Victoria, Canada; 2004, 209 pp.

32. Papazachos BC, Papaioannou ChA, Scordilis EM, et al. A forward test of the decelerating-accelerating seismic strain model to western south and Central America. Tectonophysics 2008;454:36-43. 